\title{
Design of Brain Activity Measurement for Brain ECVT Data Acquisition System
}

\author{
Rizki Edmi Edison *1, Rohmadi Rohmadi ${ }^{2}$, Sra Harke Pratama ${ }^{3}$, Muhammad Fathul Ihsan ${ }^{2}$, \\ Almusfi Saputra ${ }^{2}$, Warsito Purwo Taruno ${ }^{2}$ \\ ${ }^{1}$ Neuroscience Center, University of Muhammadiyah Prof Dr HAMKA \\ ${ }^{2}$ CTECH Labs Edwar Technology \\ ${ }^{3}$ Department of Physics, Bandung Institute of Technology \\ *Corresponding Author: Rizki Edmi Edison; rizkiedmiedison @ uhamka.ac.id
}

Received 08 September 2021;

Accepted 21 September 2021;

Published 01 October 2021

\begin{abstract}
Brain Electrical Capacitance Volume Tomography (ECVT) has been developing as an alternative non-invasive brain imaging method. In this study, brain ECVT consisting of two channels, namely a capacitance sensor, is investigated. As a comparison, EEG sensor is used to measure brain activity simultaneously with the brain ECVT. Brain activity measurements were carried out at the pre-frontal lobe of Fp1 and Fp2 locations. The resulting signal was processed by filtering method and Power Spectral Density (PSD). The result of signal analysis shows that the measurement between EEG and ECVT shows the same activity of the two modalities.
\end{abstract}

Keywords: ECVT, Brain, EEG, PSD, Capacitance

\section{Introduction}

Evaluating brain functions could be done by invasive and noninvasive method. Unfortunately, invasive method has high risks such as bleeding and infection (Gallagher et al., 2008). To minimize the adverse effects of invasive method, novel approach for measuring brain's activities should be developed. Up to now, there are many kinds of neuro-imaging technology that could be used such as fMRI (Glover, 2011), SPECT (Warwick, 2004), fNIRS (Rizki et al., 2015), and ECVT (Maharani, Edison, Ihsan, \& Taruno, 2020). In the developing country like Indonesia, it is important to find more practical, mobile, and easy-to-use technology to be used in clinical field. Therefore, ECVT that has those advantages could be considered as technology that will be used.

Tomography has been introduced since 1998 by Huang in his research using an eight-electrode capacitance sensor (Huang, Plaskowski, Xie, \& Beck, 1989). Electrical Capacitance Volume Tomography (ECVT) was developed by Warsito as an extension of 2-D Electrical Capacitance Tomography (ECT) in 2010 (Wang, Marashdeh, Fan, \& Warsito, 2010). A recent non-invasive method has been developed by combining EEG and ECVT to measure activity in the pre-frontal lobe (Ihsan et al., 2020).

This paper will describe the design of a capacitance measurement system in a brain activity scanner. Measurements were made by combining capacitance and EEG methods. Capacitance measurements are carried out using a signal source in the form of a signal generator and are read on the receiver sensor with an oscilloscope. The capacitance sensor used is a sensor with two planar electrodes surrounded by a protective ground. In the middle, an EEG sensor is placed to record the activity of an electrical signal. Measurements are made simultaneously and together between measurement of capacitance and electrical signal by the EEG.

\section{Materials and Methods}

\section{Capacitance Measurement}

The capacitance measurement method uses an AC signal by measuring the change in voltage on the receiver side of the capacitance sensor. The ECVT brain capacitance measurement system consists of (1) a signal generator, (2) two electrodes as a capacitance sensor, (3) a USB-oscilloscope to read the voltage received on the sensor into a value that can be stored on a computer, and (4) a coaxial cable that connects from the sensor to the signal generator and to the USB-oscilloscope input probe.

\section{Brain ECVT Capacitance Sensor}

This study uses a capacitance sensor consisting of two electrodes as a capacitance sensor which are positioned in parallel to each other. The electrodes are surrounded by a shielding on the back of the electrodes and around the electrodes. The ECVT brain capacitance sensor used can be seen in Fig. 1. The capacitance sensor has the dimensions of the distance between the electrodes of 
$20 \mathrm{~mm}$, the distance between the electrodes and the ground of $13 \mathrm{~mm}$, the width of the ground is $2 \mathrm{~mm}$, the size of the electrode is 20x20mm with a copper thickness of $0.05 \mathrm{~mm}$.

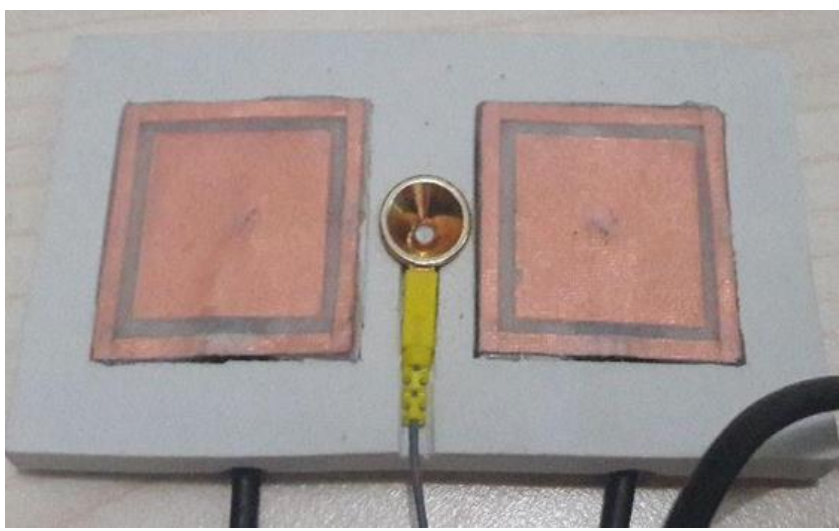

Fig 1: An Integrated Brain ECVT and EEG Sensor

\section{Signal Generator}

Capacitance measurements are carried out using AC waves. The waves are generated by the DSO 3064A Hantek signal generator. The resulting sine wave has amplitude of 20 Volt peak-to-peak with a wave frequency of $100 \mathrm{~Hz}$.

\section{EEG Measurement}

EEG measurements use a unipolar configuration where each channel uses a reference to channel A2 or A2. The EEG signal obtained is processed using EEGLab by filtering at a frequency between $0.5 \mathrm{~Hz}$ and $35 \mathrm{~Hz}$. In the EEG signal filtering process, a signal filter is also carried out with a notch filter to eliminate the influence of power line noise.

The EEG sensor used is one channel in a brain ECVT sensor set. The EEG electrode is placed in the middle between the two capacitance sensor electrodes. The position of the EEG electrodes can be seen in Fig. 1 .

\section{Measurement Procedure}

Measurement of brain activity is carried out using the method of measuring capacitance and electrical signals using EEG. A set of brain activity sensors consisting of two capacitance sensor electrodes and an EEG sensor in the middle are shown in Fig. 1. Measurements were made using two sets of brain activity sensors placed on Fp1 and Fp2 in the international 10-20 EEG system as shown in Fig. 2.

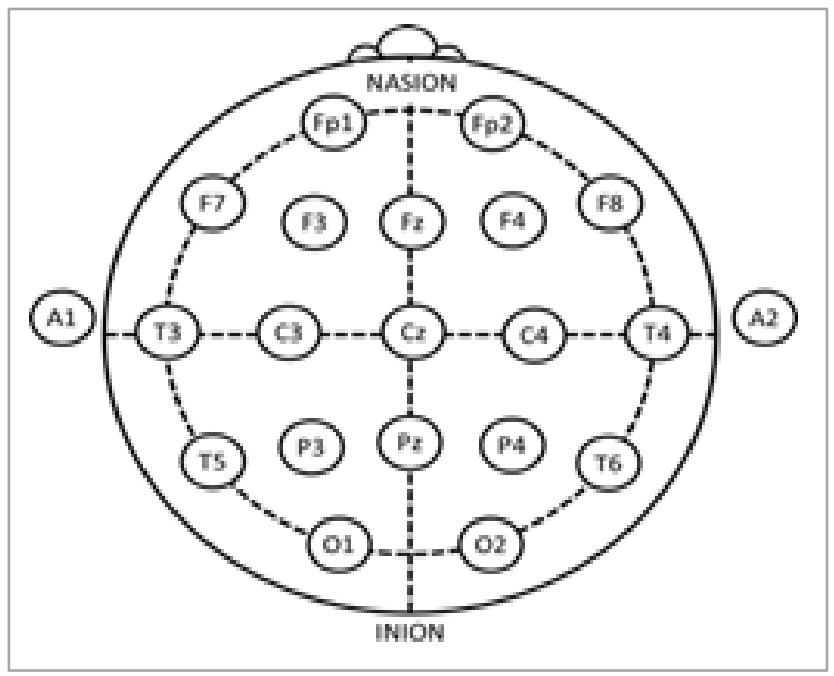

Fig 2: International 10-20 EEG Placement

\section{Experiment Setup}

Experiments were carried out using an integrated EEG-ECVT sensor. The brain ECVT sensor is positioned at Fp1 and Fp2 as shown in Fig. 3. A volunteer is wearing a brain ECVT sensor which is covered by a cap to ensure the position of the sensor does not change and the sensor remains attached to the location. Volunteers were asked to sit in a chair and face a monitor to see the stimulating display as shown in Fig. 4.

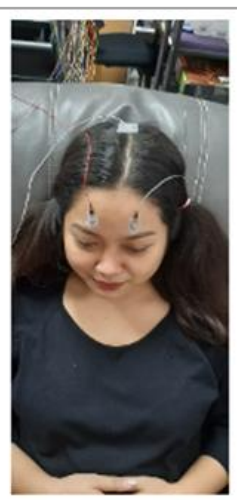

(a)

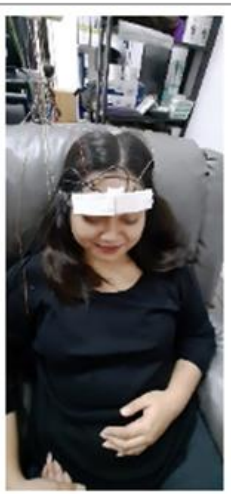

(b)

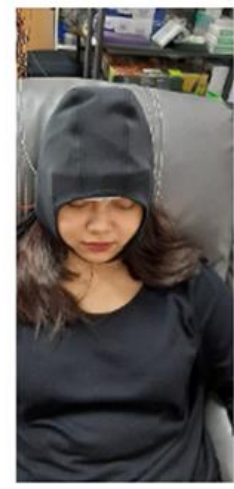

(c)
Fig 3: Integrated EEG-ECVT Sensor Placement on Subject's Head

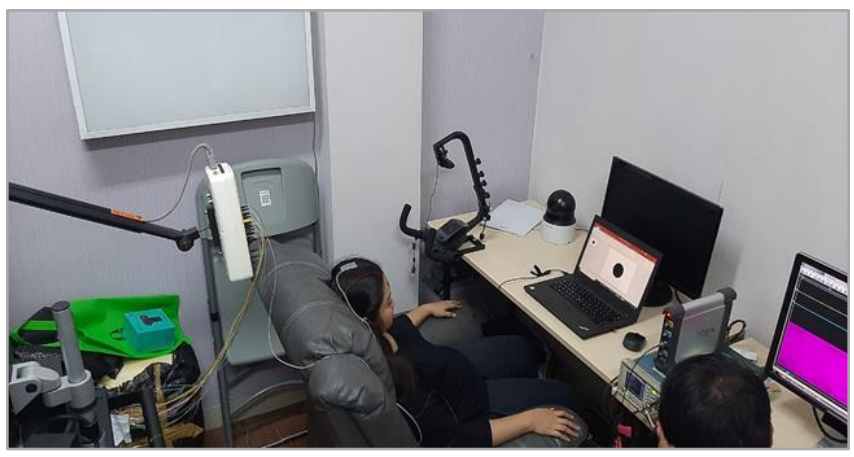

Fig 4: Integrated Multichannel EEG-ECVT Measurement Setup

The experiment was carried out for 3 minutes. In the first experiment, volunteers were asked to close their eyes for 30 seconds then open their eyes for 30 seconds. The closing and opening eyes alternate until 3 minutes. In the second experiment, volunteers were asked to close their eyes and relax for 30 seconds. Then the volunteers were asked to solve arithmetic questions for 2 minutes. Finally, the volunteers were asked to close their eyes and relax again for 30 seconds. The experimental timeline is depicted as in Fig. 5.

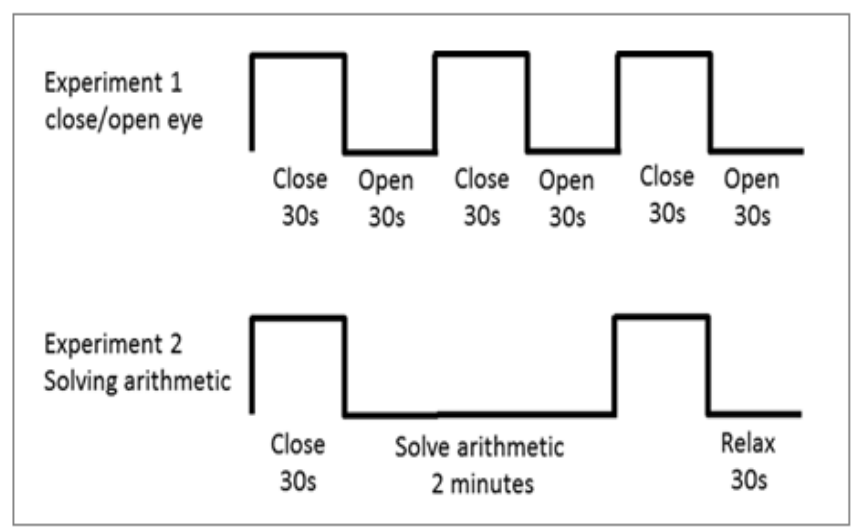

Fig 5: Experiment Timeline 


\section{Data Acquisition Process}

The brain ECVT measurement consists of two channels. Each channel consists of a two-electrode capacitance sensor and one EEG sensor electrode which is illustrated in the block diagram in Fig. 6.

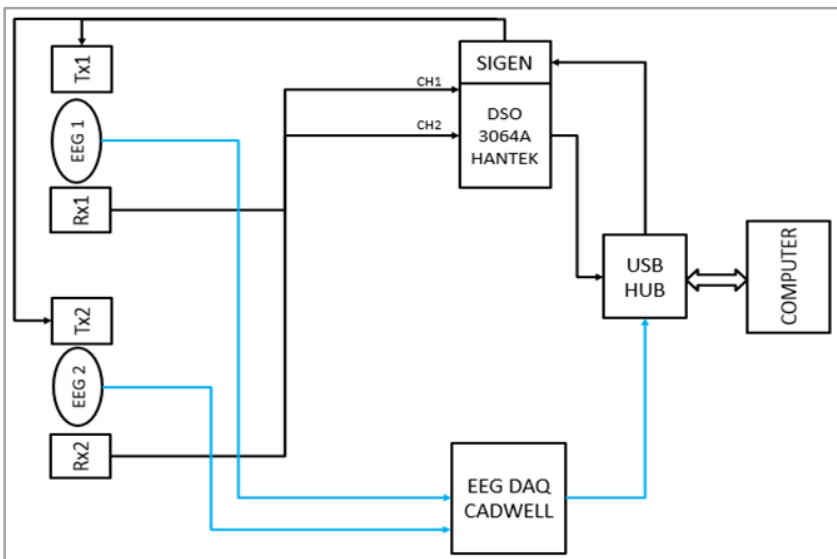

Fig 6: Block Diagram of Measuring Method for Brain ECVT

First, the capacitance transmitter sensor is connected to the signal generator output (SIGEN) with a coaxial cable. This is done on all ECVT brain transmitter sensors. The capacitance receiver sensors are connected to the USB-oscilloscope input (DSO 3064A HANTEK) with a coaxial cable. This is also done to the capacitance receiver sensor on the other channel. The EEG electrode sensor is connected to the EEG DAQ CADWELL using an EEG cable. The data acquisition process uses acquisition software that has been prepared.

EEG data acquisition process uses software specially designed for EEG DAQ CADWELL. The data recorded were raw data from electrical readings on the EEG probe and visual video of the conditions of volunteers at the time of the experiment. Visual records serve as secondary data to validate volunteer activities during the experiment.

The EEG signal is processed using a band pass filter by allowing $0.5 \mathrm{~Hz}$ to $35 \mathrm{~Hz}$ frequency signals. In addition, the process

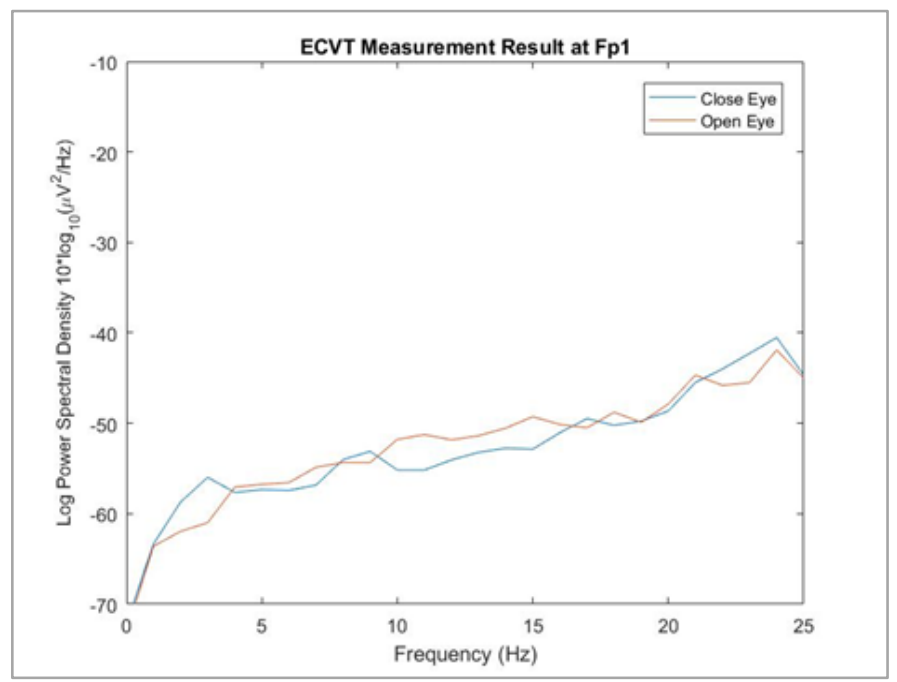

(a) of eliminating the influence of noise originating from the electric grid (power line) is also carried out by using a notch filter. The EEG signal is processed using the power spectral density (PSD) method. This method is to filter the signal and calculate the signal power at each contained frequency.

The capacitance signal was acquired using a digital storage oscilloscope (DSO) 3064A HANTEK. DSO 3604A has two functions, as a signal generator and as a sensor output signal reader by converting the voltage into a digital quantity. The acquisition process uses the interface software provided by HANTEK by generating voltage raw data from the DSO input. The resulting raw data is a signal from analog wave sampling from the output of the capacitance sensor. The data collection process using EEG and ECVT was carried out at the same time to get the same results for each experiment.

The process of capturing capacitance signal data is carried out everyone experimental condition. The recorded data is then saved into one file in the form of raw data.

Raw data for capacitance signals are processed using the PSD method to be compared with the same process data from the EEG signal. The resulting data can show the difference in the intensity of the signal received.

\section{Results and Discussion}

ECVT brain acquisition data is tested to determine and evaluate system performance. Tests are carried out to determine the ability of the USB-oscilloscope whether it can acquire a signal with a frequency that will be generated in accordance with the known brain signal. Experiment of signal data acquisition with brain wave frequencies was carried out by trying to acquire waves with frequencies of $5 \mathrm{~Hz}, 7 \mathrm{~Hz}, 9 \mathrm{~Hz}, 10 \mathrm{~Hz}, 20 \mathrm{~Hz}, 30 \mathrm{~Hz}, 40 \mathrm{~Hz}$ and $50 \mathrm{~Hz}$.

Experiments with volunteers were carried out in three conditions: volunteers opened their eyes, volunteers closed their eyes and volunteers solved simple arithmetic problems.

The raw ECVT brain data is filtered with a bandpass filter from $0.5 \mathrm{~Hz}$ to $25 \mathrm{~Hz}$ and a $50 \mathrm{~Hz}$ notch filter. The results of the signal filter against the ECVT brain raw data displayed using the PSD method can be seen in Fig.7.

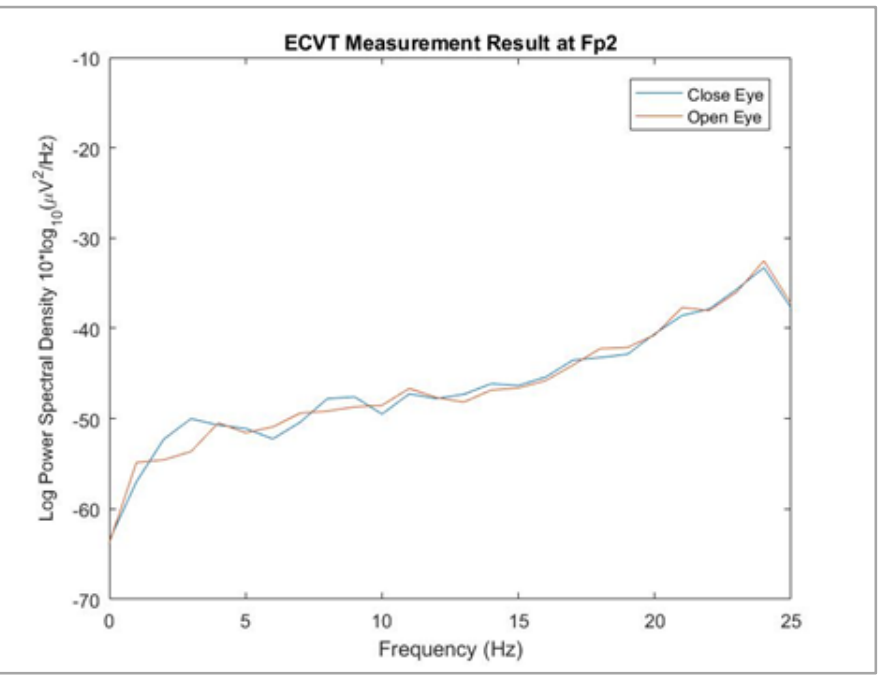

(b) 


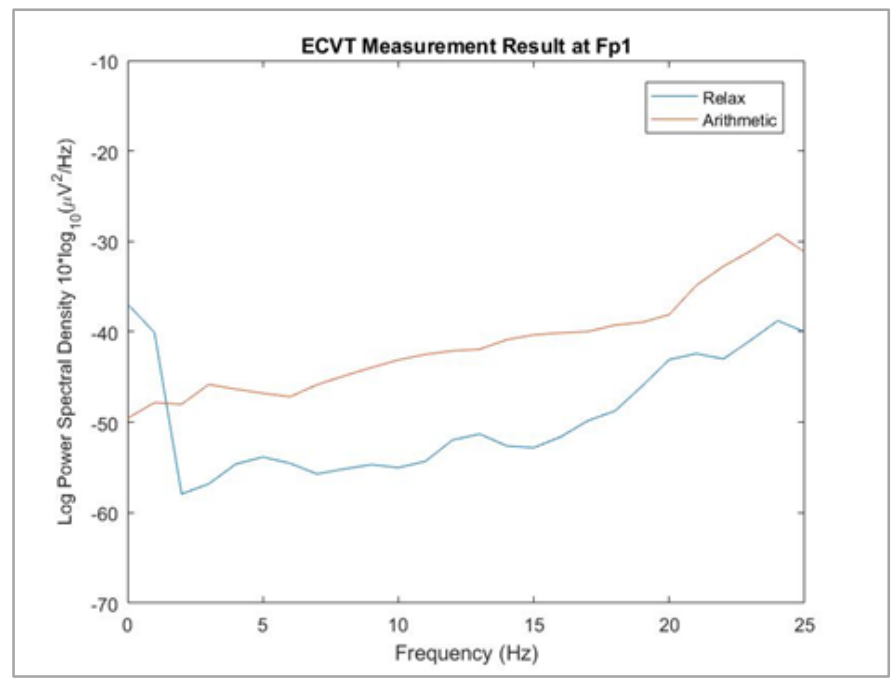

(c)

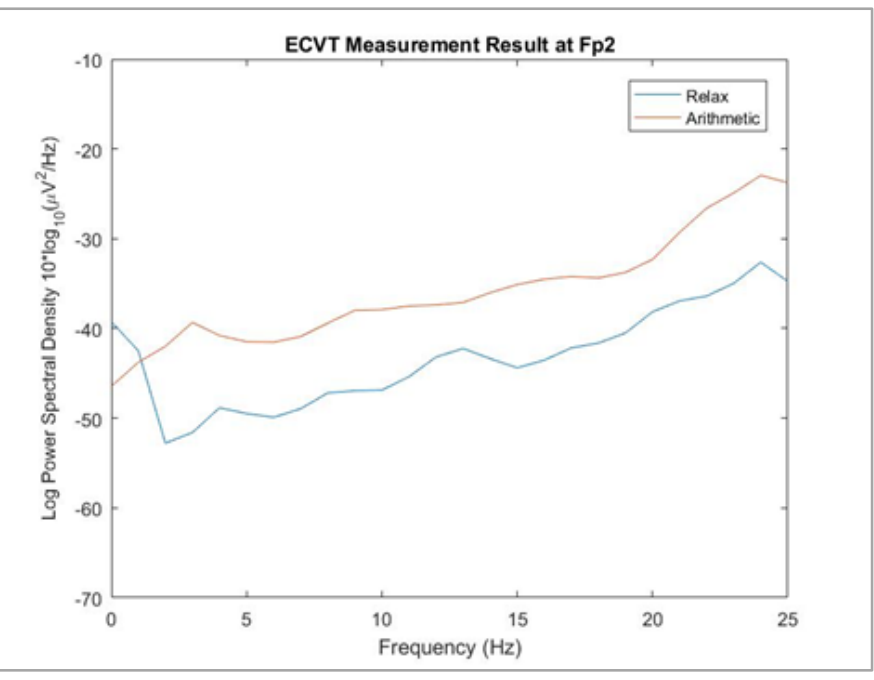

(d)

Fig 7: Power Spectral Density (PSD) of the ECVT Signals

Fig. 8. Shows the results of EEG data processing using the same PSD method. The EEG signal is during closing eyes on the Fp1 and Fp2 channels. Fig. 8. (a) shows the PSD of the volunteer signal when closing their eyes at Fp1 location. Fig. 8. (b) shows the PSD signal during closing eyes at Fp2 location.

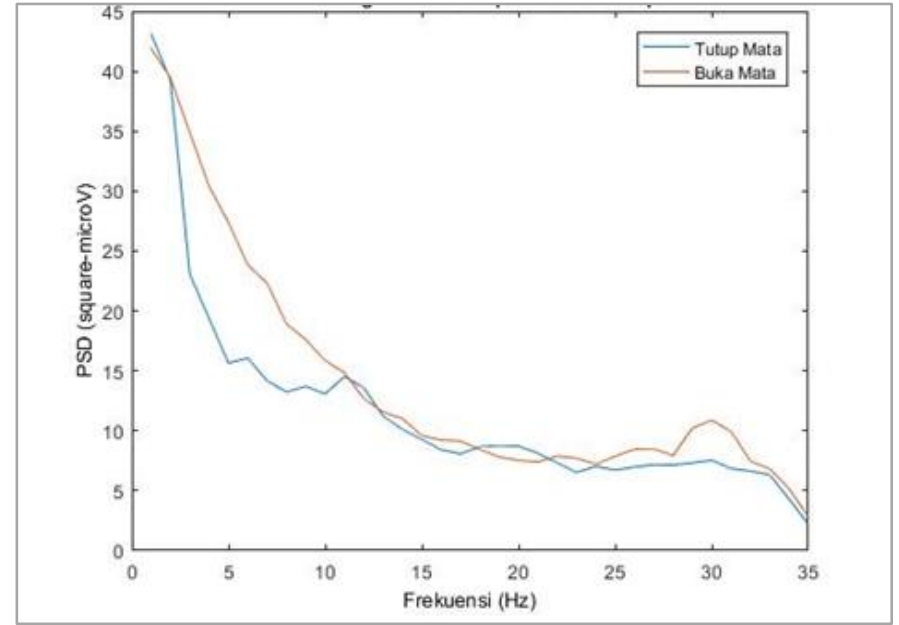

(a)

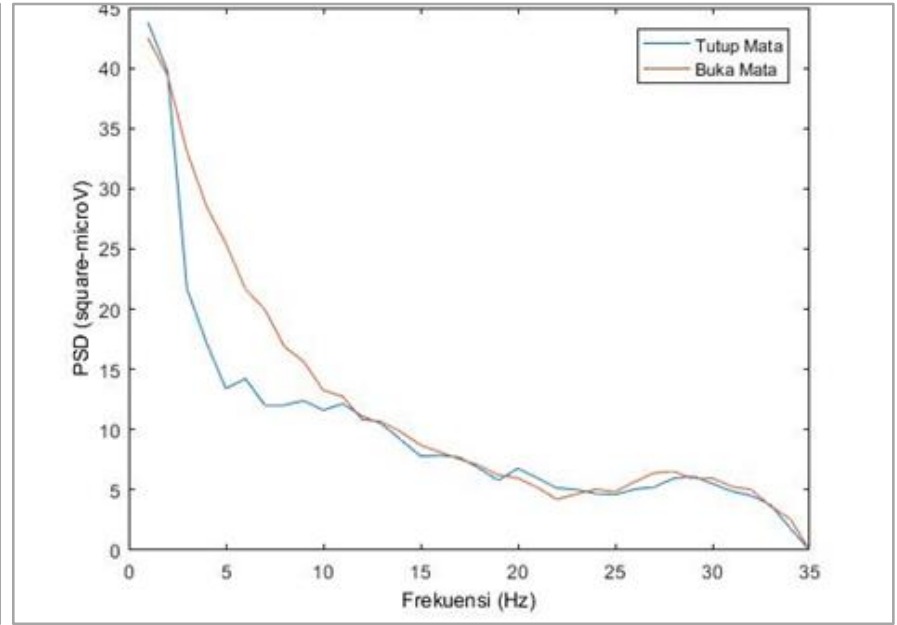

(b)

Fig 8: Power Spectral Density (PSD) of the EEG Signals

This study shows that the measurement of brain activity with a brain ECVT consisting of a capacitance sensor and an EEG sensor can detect brain activity at the Fp1 and Fp2 locations in each given stimulus. From the PSD, each signal indicating the activity of closing the eyes and opening the eyes can be clearly distinguished. In future studies, it is necessary to improve the measurement of brain activity with brain ECVT with a greater number of channels.

\section{Ethics Approval and Consent to Participate}

Ethics of research is approved by Ethical Committee of UHAMKA and all participants that involved in this study were read, understood, signed the inform consent for the study.

\section{List of Abbreviations}

ECVT: Electrical Capacitance Volume Tomography fMRI: Functional Magnetic Resonance Imaging SPECT: Single-Photon Emission Computed Tomography $\underline{\text { Www.ijirms.in }}$
fNIRS: functional Near-Infrared Spectroscopy EEG: Electroencephalography PSD: Power Spectral Density

\section{Data Availability}

For further information about raw data of study, please send e-mail to correspondent author.

\section{Conflicts of Interest}

All authors declare that there is no conflict of interest regarding the publication of this paper.

\section{Authors' contributions}

REE conceptualized the research, wrote major part of manuscript, and performed examination; RR analyzed the data and wrote part of manuscript; SHP analyzed the data; 
MFI performed ECVT operation; AS analyzed the data; and WPT conceptualized the research.

\section{References}

[1] Gallagher, A., Lassonde, M., Bastien, D., Vannasing, P., Lesage, F., Grova, C., Bouthillier, A., Carmant, L., Lepore, F., Béland, R., \& Nguyen, D. K. (2008). Noninvasive pre-surgical investigation of a 10 year-old epileptic boy using simultaneous EEG-NIRS. Seizure. doi:10.1016/j.seizure.2008.01.009

[2] Glover, G. H. (2011). Overview of functional magnetic resonance imaging. Neurosurgery Clinics of North America. doi:10.1016/j.nec.2010.11.001

[3] Huang, S. M., Plaskowski, A. B., Xie, C. G., \& Beck, M. S. (1989). Tomographic imaging of two-component flow using capacitance sensors. Journal of Physics E: Scientific Instruments. doi:10.1088/0022-3735/22/3/009

[4] Ihsan, M. F., Edison, R. E., Pratama, S. H., Saputra, A., Rohmadi, R., \& Taruno, W. P. (2020). Real-Time Measurement of Integrated Multichannel EEG-ECVT in Pre-Frontal Lobe. European Journal of Molecular \& Clinical Medicine, 7(10), 1343-1350.

[5] Maharani, R., Edison, R. E., Ihsan, M. F., \& Taruno, W. P. (2020). Average Subtraction Method for Image Reconstruction of Brain using ECVT for Tumor Detection. International Journal of Technology. doi:10.14716/ijtech.v11i5.4325

[6] Rizki, E. E., Uga, M., Dan, I., Dan, H., Tsuzuki, D., Yokota, H., Oguro, K., \& Watanabe, E. (2015). Determination of epileptic focus side in mesial temporal lobe epilepsy using long-term noninvasive fNIRS/EEG monitoring for presurgical evaluation. Neurophotonics. doi:10.1117/1.nph.2.2.025003

[7] Wang, F., Marashdeh, Q., Fan, L. S., \& Warsito, W. (2010). Electrical capacitance volume tomography: Design and applications. Sensors. doi:10.3390/s100301890

[8] Warwick, J. M. (2004). Imaging of brain function using SPECT. Metabolic Brain Disease. doi:10.1023/B:MEBR.0000027422.48744.a3

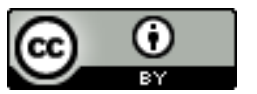

Open Access This article is licensed under a Creative Commons Attribution 4.0 International License, which permits use, sharing, adaptation, distribution and reproduction in any medium or format, as long as you give appropriate credit to the original author(s) and the source, provide a link to the Creative Commons license, and indicate if changes were made. The images or other third party material in this article are included in the article's Creative Commons license, unless indicated otherwise in a credit line to the material. If material is not included in the article's Creative Commons license and your intended use is not permitted by statutory regulation or exceeds the permitted use, you will need to obtain permission directly from the copyright holder. To view a copy of this license, visit https://creativecommons.org/licenses/by/4.0/.

(C) The Author(s) 2021 